\title{
Inflammatory Pseudotumor of the Urinary Bladder
}

\author{
Elsa Rosado ${ }^{1 *}$, José Pereira $^{2}$, Florence Corbusier ${ }^{3}$, Pieter Demeter $^{4}$, Maria Antonietta Bali ${ }^{3}$ \\ 1. Department of Radiology, Hospital Fernando Fonseca, Amadora, Portugal \\ 2. Department of Radiology, Centro Hospitalar Lisboa Central, Lisbon, Portugal \\ 3. Department of Radiology, Hôpital Erasme, Brussels, Belgium \\ 4. Department of Pathology, Hôpital Erasme, Brussels, Belgium
}

* Correspondence: Elsa Sofia Sousa Prata Rosado Rodrigues, Hospital Fernando Fonseca, IC 19, Venteira, 2720-276, Amadora, Portugal (入elsasprr@hotmail.com)

Radiology Case. 2015 Jan; 9(1):36-42 :: DOI: 10.3941/jrcr.v9i1.2066

\begin{abstract}
We report a case of an inflammatory pseudotumor of the urinary bladder in a 31 year-old woman. She presented at the emergency room with low abdominal pain and urinary symptoms. Abdominal ultrasound, computed tomography and magnetic resonance imaging were performed and revealed asymmetric thickening of the urinary bladder wall. Cystoscopy with urinary cytology revealed a benign nature of the process. The patient underwent partial cystectomy and the pathologic examination of the specimen revealed an inflammatory pseudotumor. We reviewed the clinical, imaging and pathological features of the inflammatory pseudotumor of the urinary bladder and discussed its differential diagnosis.
\end{abstract}

\section{CASE REPORT}

\section{CASE REPORT}

A 31 year-old female patient, with no relevant medical history, presented at the emergency room complaining of abdominal pain in the hypogastrium and right iliac fossa, since 13 days. Additional symptoms included dysuria, nocturia, frequency and macroscopic hematuria. She had no fever or other additional complains. Symptoms did not improve despite antibiotic therapy (cefuroxime). Physical examination showed discomfort at hypogastric palpation, without rebound tenderness. Blood tests and urine analysis were normal.

Pelvic ultrasound demonstrated a thickened anterolateral urinary bladder wall (maximum thickness: $21 \mathrm{~mm}$ ). There was a round, hypoechoic area $(19 \mathrm{~mm}$ diameter $)$ within the thickened wall (Fig.1). The surrounding fat was infiltrated (Fig. 1). Doppler imaging showed flow within the mass (Fig. $1)$.
A contrast-enhanced Computed Tomography (CT) was performed and confirmed the presence of the urinary bladder wall thickening. Multiple papillary projections were present, protruding from the thickened wall. A hypoenhancing area (20 $\mathrm{mm}$ diameter) with hyperenhancing borders was noted within the thickened urinary bladder wall (Fig. 2).

Pelvic Magnetic Resonance imaging (MR) was performed for further characterization. The parietal thickening of the right lateral wall of the urinary bladder was centered on a nodular formation with $20 \mathrm{~mm}$ diameter showing an intermediate signal intensity on $\mathrm{T} 1$ and $\mathrm{T} 2$ weighted images (Fig.3). This lesion was positive on diffusion weighted images (Fig. 4). Multiple papillary projections were noted on the luminal border of the thickened urinary bladder wall (Fig. 3). The other pelvic organs had no signs of disease and there were no pelvic adenopathies. 
A cystoscopy was then performed and urinary cytology revealed no neoplastic cells, suggesting a benign nature of the lesion. The patient underwent a partial cystectomy, without complications. The pathologic examination of the resected specimen revealed a lesion of $2,3 \times 2 \times 2 \mathrm{~cm}$, with a brownyellow surface and white section (Fig.5). Microscopy showed myofibroblastic spindle cells proliferation and a mixed inflammatory infiltrate, containing lymphocytes, neutrophils and eosinophils (Fig. 6). These findings were diagnostic of an inflammatory pseudotumor of the urinary bladder.

Four months after surgery the patient is well and there are no signs of recurrence. Follow-up ultrasound examinations revealed a residual, stable, thickening of the anterolateral urinary bladder wall, corresponding to a fibrous post-operative sequel.

\section{DISCUSSION}

\section{Etiology \& demographics}

Inflammatory pseudotumor of the urinary bladder is a rare benign condition of unknown etiology [1]. Several predisposing factors have been described, such as recurrent cystitis and prior urinary bladder surgery, but the cause and the pathogenesis remains controversial [2]. Inflammatory pseudotumor is characterized histologically by the presence of inflammatory cells with a variable fibrous response [1]. Microscopic pattern is biphasic: in superficial areas there is a paucicellular spindle cell proliferation mixed with mostly chronic inflammation. The deeper areas of the tumor have more densely cellular interlacing storiform fascicles of spindle cells. Focal nuclear and nucleolar enlargement is attributable to reactive atypia [3].

Inflammatory pseudotumors are rare, with 81 cases described in the urinary bladder. Male to female ratio was 11:6 in one series of 17 cases [3]. It can occur at any age, but typically appears in young adults, with an average age of 28 years [1]

\section{Clinical \& imaging findings}

The most common initial manifestation is painless gross hematuria, which may result in anemia. Other symptoms may include frequency of urination and dysuria. Urinary tract obstruction may also occur [1].

At imaging, inflammatory pseudotumor of the urinary bladder usually appears as a single mass, which may be exophytic or polypoid [4]. Some lesions are poorly defined and may extend into the perivesical fat [5]. It may be found at any site in the urinary bladder, however, the trigone tend to be spared $[1,4]$. Ultrasound findings are non-specific and include hypoechoic or hyperechoic lesions with either ill-defined or well-circumscribed borders. These lesions often have increased vascularity during color or power Doppler examinations. CT also shows varying appearances; lesions can have $1 \mathrm{ow}$, equal, or high attenuation compared with the surrounding tissue. On MR images, inflammatory pseudotumor usually has low signal intensity on both $\mathrm{T} 1$ - and T2-weighted images, which reflect the fibrotic nature of these lesions [6]. Contrast enhanced CT and MR usually demonstrate early peripheral enhancement. This finding can be explained by the histological arrangement of the lesion, with spindle cells, blood vessels and inflammatory cells at the peripheral area [5]. Delayed imaging often shows increasing enhancement due to the presence of fibrosis [6].

The variable radiologic findings may be attributed to vary degrees of fibrosis and cellular infiltration [1]. Imaging findings are nonspecific and histologic confirmation is essential [4].

\section{$\underline{\text { Treatment \& prognosis }}$}

Inflammatory pseudotumor of the urinary bladder usually follows a benign clinical course. Therefore, the optimal curative management is conservative surgery in the form of transurethral tumor resection or partial cystectomy. There are no reports of either local recurrence or distal metastasis [2]. Some cases of spontaneous regression have been reported, which may be a reflection of the inflammatory nature of the lesion [6].

\section{Differential Diagnoses}

Differential diagnosis includes several neoplastic and nonneoplastic conditions, such as epithelial carcinoma, leiomyoma, endometriosis and infection [4].

Urothelial carcinoma is the most common urinary tract cancer in the United States and Europe, accounting for $90 \%$ of all urinary bladder cancers. Squamous cell carcinoma accounts for $2-15 \%$ and adenocarcinoma for less than $2 \%$ of urinary bladder neoplasms. Much rarer tumors are lymphoma, sarcoma, neuroendocrine carcinoma, carcinoid and melanoma. Urothelial tumors usually occur in patients older than 65 years. Most tumors are located at the urinary bladder base and $40 \%$ are multiple at the initial diagnosis. They can be papillary, sessile, or nodular. At ultrasound they appear as papillary, hypoechoic masses or as areas of focal wall thickening. At CT, urothelial carcinoma appears as an intraluminal papillary or nodular mass or focal wall thickening, with associated tumoral calcification in approximately $5 \%$ of cases. At MR, urothelial tumors have intermediate signal intensity on $\mathrm{T} 2$-weighted images, contrasting with the high signal intensity of urine and low signal intensity of muscle. After contrast administration, urinary bladder cancer shows avid and early enhancement, both on CT and MR [7]. Distinctly to urothelial carcinoma, inflammatory pseudotumor occurs in a younger age group, usually appears as a single urinary bladder mass and tends to spare the trigone. Enhancement characteristics may help to distinguish these two entities as urothelial carcinoma enhances avidly and inflammatory pseudotumor has ring like enhancement with a hypoenhancing central region. However, histological confirmation is essential to distinguish inflammatory pseudotumor from urothelial carcinoma.

Leiomyomas arise in the submucosa, but growth may be submucosal, intravesical, or extravesical. Ultrasound and CT show smooth, solid, homogeneous masses. Typically, leiomyomas exhibit intermediate signal intensity on T1weighted images and low signal intensity on T2-weighted images. Contrast enhancement is variable, with degenerated areas lacking enhancement. It can be difficult to distinguish leiomyoma from leiomyosarcoma at imaging. Necrosis is common in leiomyosarcomas, which tend to be poorly 
circumscribed invasive masses. Consequently, they are more heterogeneous on T2-weighted images and demonstrate nonenhancing areas secondary to necrosis [7].

Urinary bladder endometriosis can occur spontaneously or following pelvic surgery. Urinary bladder implants typically occur at the vesicouterine pouch [4]. Localized urinary bladder wall thickening can be appreciated at ultrasound [8]. The typical MR features are hemorrhagic foci with high signal intensity on fat-suppressed and non-fat suppressed T1weighted images. Urinary bladder endometriosis may also have high signal intensity on T2-weighted images. Endometriotic masses may enhance, either homogeneously or peripherally [4].

Urinary bladder schistosomiasis is caused by schistosoma haematobium species. In the acute phase, nodular urinary bladder wall thickening is seen on ultrasound, CT and MR. The chronic phase is characterized by a contracted, fibrotic, thick-walled urinary bladder with calcifications. A mass may be secondary to inflammation or complicating carcinoma, typically squamous cell carcinoma [4].

Tuberculosis of the urinary bladder is uncommon in western countries. Almost all cases of urinary bladder involvement result from the downward spread of the disease along the urinary tract [4]. Early TB cystitis produces mucosal ulceration and edema. Ultrasound may demonstrate diffuse irregular wall thickening. Mucosal edema at the trigone can cause ureteric obstruction. In advanced disease, inflammation progresses to involve the muscularis layer. Subsequent mural fibrosis leads to a thickened and contracted urinary bladder. Therefore, the most common manifestation of TB cystitis is a reduced urinary bladder capacity with wall thickening [9]. Urinary bladder tuberculosis may be complicated by fistulas or sinus tract formation, although these complications are rare and are demonstrated better on CT or MR [4].

\section{TEACHING POINT}

Inflammatory pseudotumor of the urinary bladder is a rare disease of unknown etiology, characterized by an exophytic or polypoid mass with heterogeneous appearance and peripheral enhancement after contrast administration. Conservative surgery is curative, with no recurrence reported.

\section{REFERENCES}

1. Park SB, Cho KS, Kim JK, et al. Inflammatory pseudotumor (myoblastic tumor) of the genitourinary tract. AJR Am J Roentgenol. 2008;191(4)1255-62. PMID: 18806173

2. Kumar A, Bhatti SS, Sharma S, Gupta SD, Kumar R. Inflammatory pseudotumor of urinary bladder - a diagnostic and management dilemma. Int Urol Nephrol. 2007;39(3):799-802. PMID: 17333528

3. Iczkowski KA, Shanks JH, Gadaleanu V, et al. Inflammatory pseudotumor and sarcoma of urinary bladder: differential diagnosis and outcome in thirty-eight spindle cell neoplasms. Mod Pathol. 2001;14(10):1043-51. PMID: 11598176

4. Wong-You-Cheong JJ, Woodward PJ, Manning MA, Davis CJ. From the archives of the AFIP: Inflammatory and nonneoplastic bladder masses: radiologic-pathologic correlation. Radiographics. 2006;26(6):1847-68. PMID: 17102055

5. Sugita R, Saito M, Miura M, Yuda F. Inflammatory pseudotumour of the bladder: CT and MRI findings. Br J Radiol. 1999;72(860):809-11. PMID: 10623450

6. Patnana M, Sevrukov AB, Elsayes KM, Viswanathan C, Lubner M, Menias CO. Inflammatory pseudotumor: the great mimicker. AJR Am J Roentgenol. 2012;198(3):W21727. PMID: 22358018

7. Wong-You-Cheong JJ, Woodward PJ, Manning MA, Sesterhenn IA. From the Archives of the AFIP: neoplasms of the urinary bladder: radiologic-pathologic correlation. Radiographics. 2006;26(2):553-80. PMID: 16549617

8. Balleyguier C, Chapron C, Dubuisson JB, et al. Comparison of magnetic resonance imaging and transvaginal ultrasonography in diagnosing bladder endometriosis. J Am Assoc Gynecol Laparosc. 2002;9(1):15-23. PMID: 11821601

9. Muttarak M, ChiangMai WN, Lojanapiwat B. Tuberculosis of the genitourinary tract: imaging features with pathological correlation. Singapore Med J. 2005;46(10):568-74. PIMD: 16172781 
FIGURES

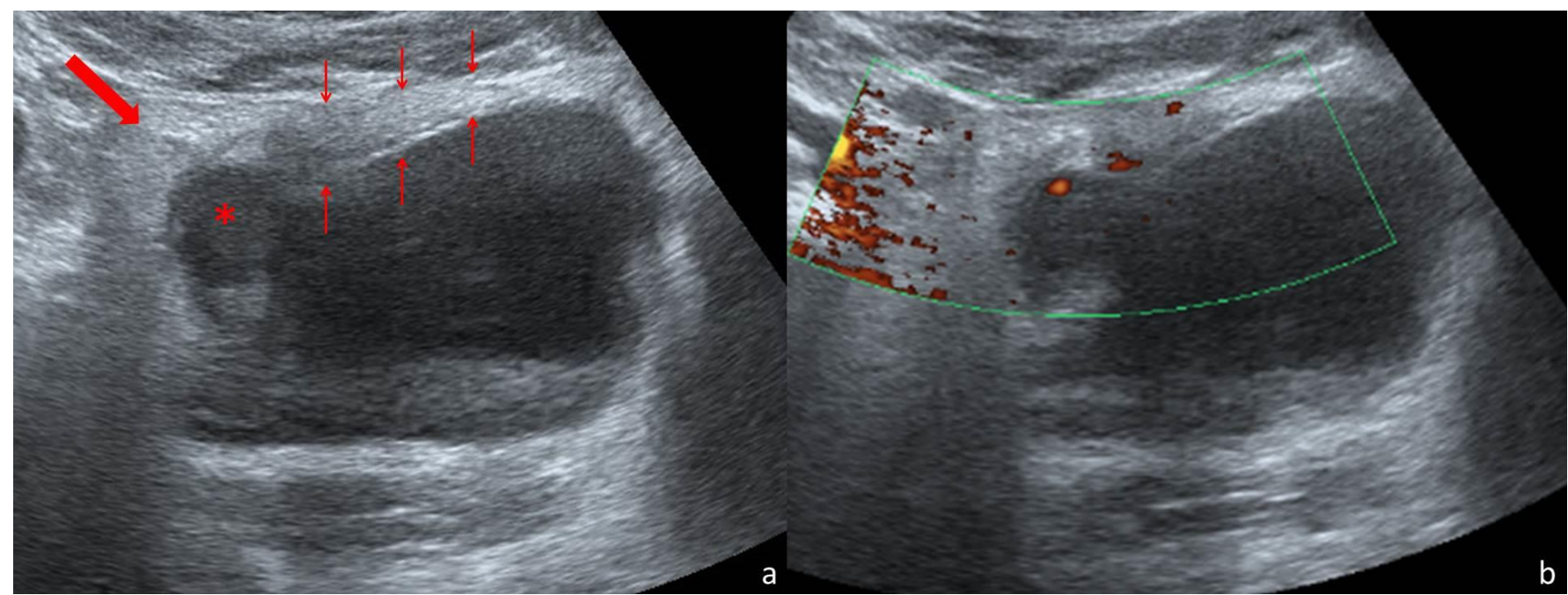

Figure 1: Thirty-one year old woman with inflammatory pseudotumor of the urinary bladder. Abdominal US scan performed with a convex array transducer (3-6MHz) on a Toshiba Aplio 500®. Axial scanning plane through the hypogastrium (a) demonstrates the partially filled urinary bladder, with a thickened wall (thin arrows). Maximum thickness was $21 \mathrm{~mm}$. In the right-anterior segment of the thickened wall there is a round, hypoechoic area (*) of $19 \mathrm{~mm}$ diameter. The surrounding fat is hyperechoic (thick arrow). Power Doppler imaging in the same axial scanning plane (b) shows vascularization within the thickened wall.

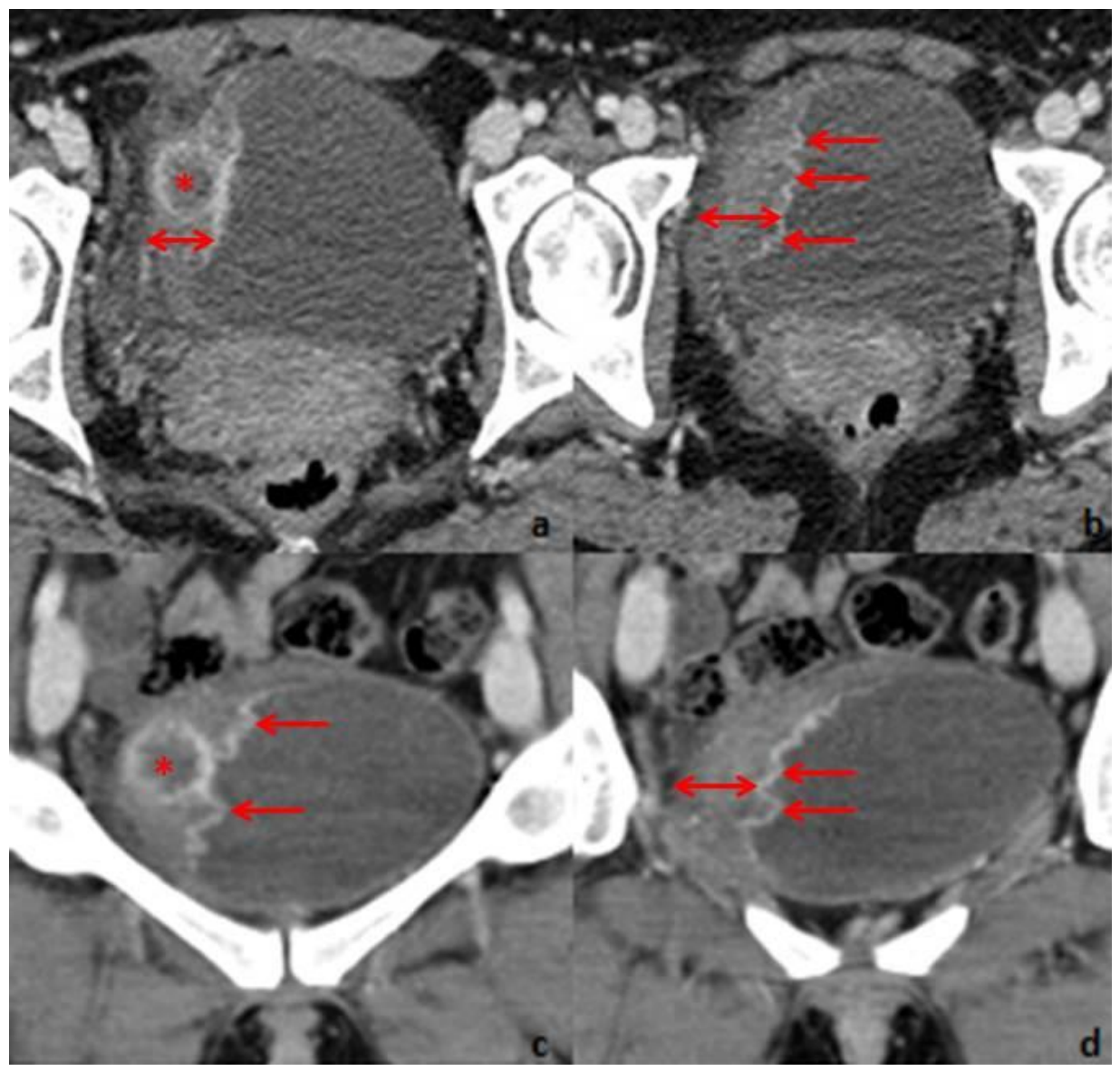

Figure 2: Thirty-one year old woman with inflammatory pseudotumor of the urinary bladder. Contrast-enhanced CT, performed with a SimensSensation ${ }^{\circledR}(64$ slice-CT). Radiation dose: $120 \mathrm{Kv}$ and $70 \mathrm{mAs}$. Injection of $120 \mathrm{ml} \mathrm{of} 400 \mathrm{mg} / \mathrm{ml}$ iodine concentration non-ionic contrast agent (Iomeron $\left.{ }^{\circledR}\right)$. Images selected were taken 60 s after contrast injection. Axial 1,5 thickness images ( $\mathrm{a}$ and $\mathrm{b}$ ) and coronal $4 \mathrm{~mm}$ thickness reconstruction images ( $\mathrm{c}$ and $\mathrm{d}$ ) demonstrate right lateral bladder wall thickening (double arrow). Maximum thickness is $21 \mathrm{~mm}$. The mucosal surface is rim enhancing and has multiple papillary projections protruding into the urinary bladder lumen. Within the thickened wall, there is a nodular, $20 \mathrm{~mm}$ diameter hypoenhancing area $(*)$ with hyperenhancing margins. 


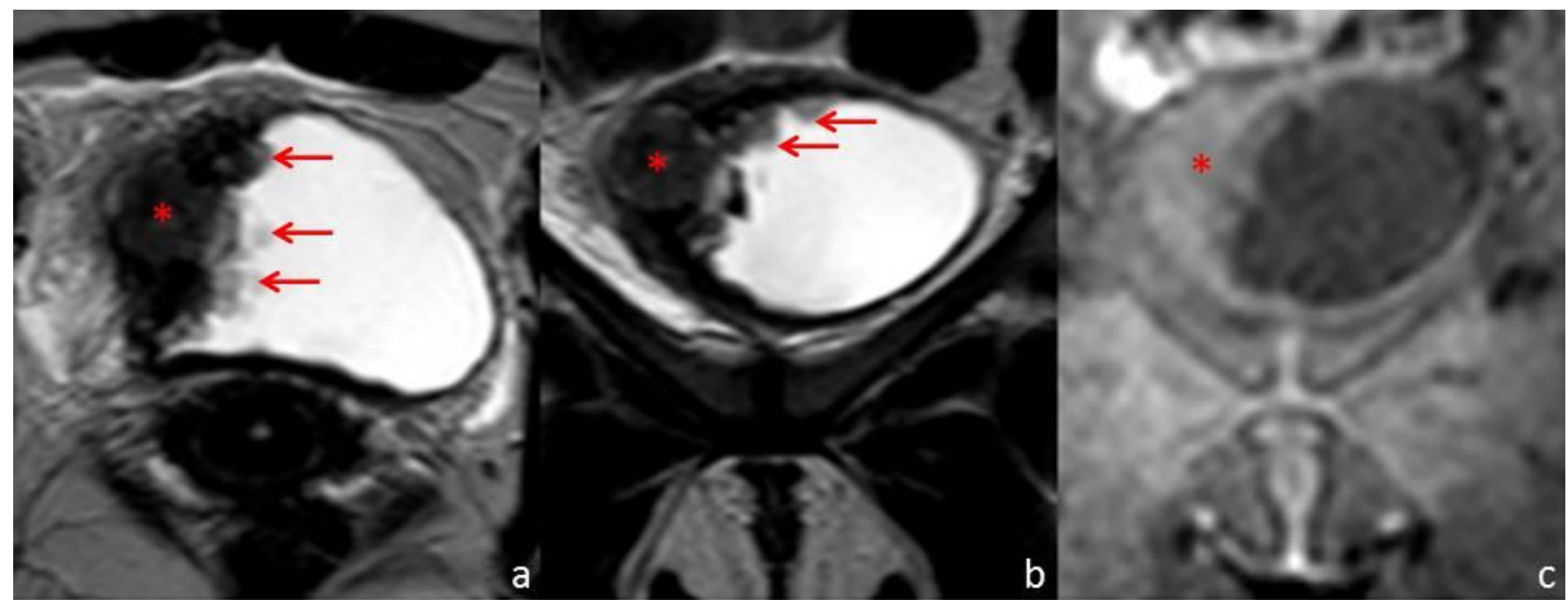

Figure 3: Thirty-one year old woman with inflammatory pseudotumor of the urinary bladder. Pelvic MR performed with a Philips Intera ${ }^{\circledR}(1,5 \mathrm{~T})$. T1-weighted images were obtained by $3 \mathrm{D}$ spoiled turbo gradient echo technique (TR/TE: 3,25/1,55 ms) with SPAIR fat suppression and SENSE acceleration (factor 2). T2-weighted images were obtained by spin-echo technique (TR/TE: 8148/150 ms). Axial T2-weighted (a), coronal T2-weighted (b) and coronal T1-weighted (c) images demonstrate the right urinary bladder wall thickening with a nodular solid area $\left(^{*}\right)$ of intermediate signal on the T2-weighted images and which is almost imperceptible on the T1-weighted image. The mucosal surface of the thickened wall has multiple papillary projections, well depicted on the T2-weighted images (arrows).

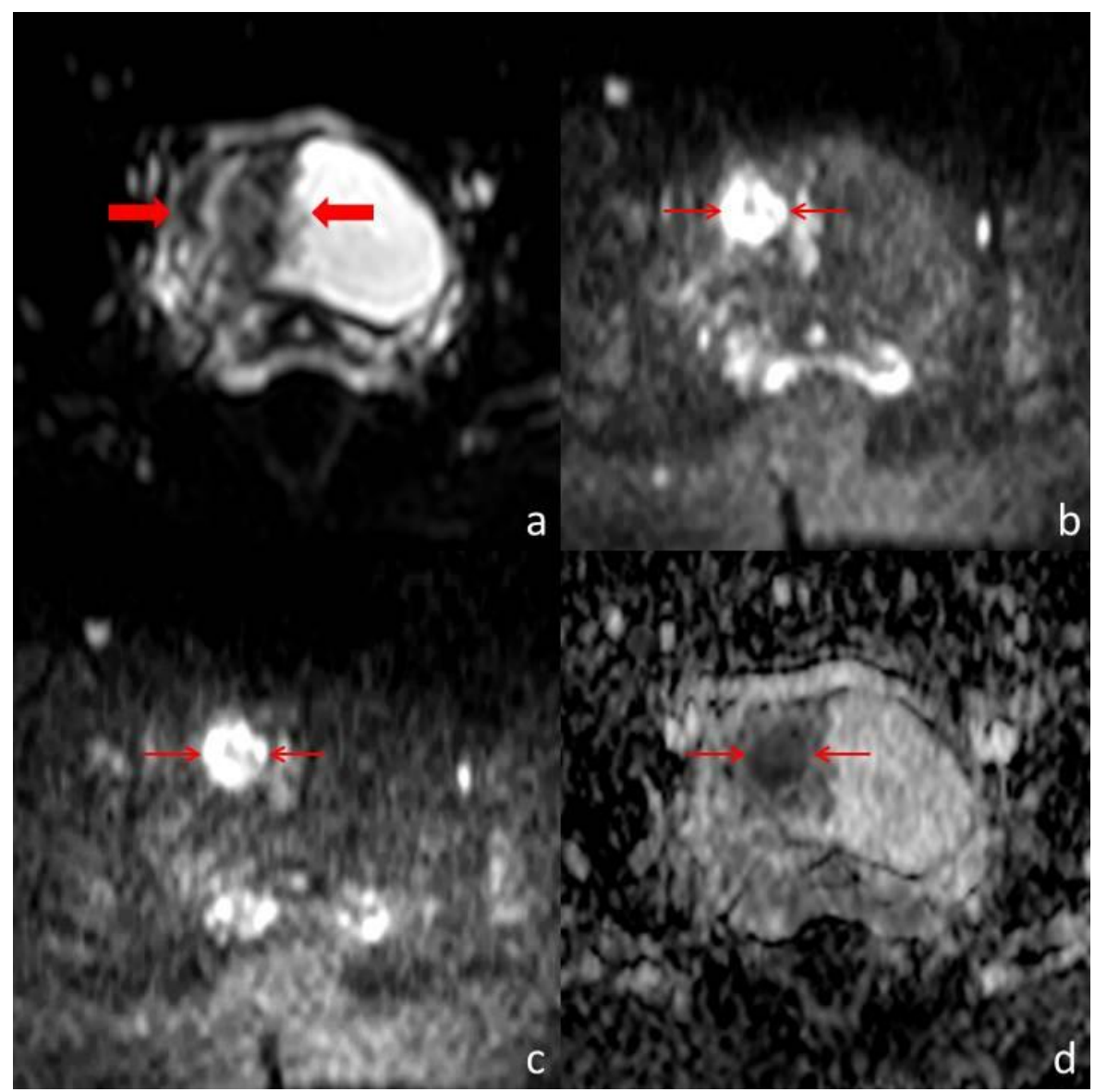

Figure 4: Thirty-one year old woman with inflammatory pseudotumor of the urinary bladder. Pelvic MR performed with a Philips Intera ${ }^{\circledR}(1,5 \mathrm{~T})$. Diffusion-weighted images were obtained by echo planar imaging technique, with a TR/TE/TI of $1300 / 180 / 90 \mathrm{~ms}$ and a b value of $0 \mathrm{~s} / \mathrm{mm} 2$ (a), $1000 \mathrm{~s} / \mathrm{mm} 2$ (b) and $1500 \mathrm{~s} / \mathrm{mm} 2$ (c). ADC maps were built based on the three $\mathrm{b}$ values (d). The parietal thickening (thick arrows) is well depicted on (a). At higher b values, the diffusion restriction of the nodular component of the lesion is evident (thin arrows), demonstrating its high cellularity. This area has lower signal intensity in the ADC map, confirming restricted diffusion. 


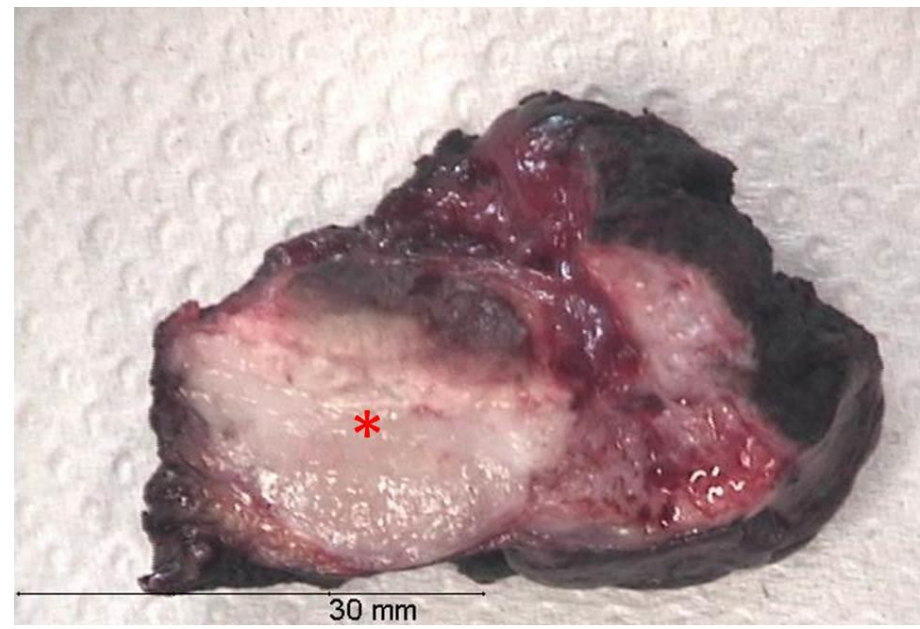

Figure 5 (left): Thirty-one year old woman with inflammatory pseudotumor of the urinary bladder. Gross examination of the surgical specimen. The resected piece measured $4,5 \times 4 \times 2 \mathrm{~cm}$. The lesion had $2,3 \times 2 \times 2 \mathrm{~cm}$ and it was completely resected. In cross section (*) it was white and firm.

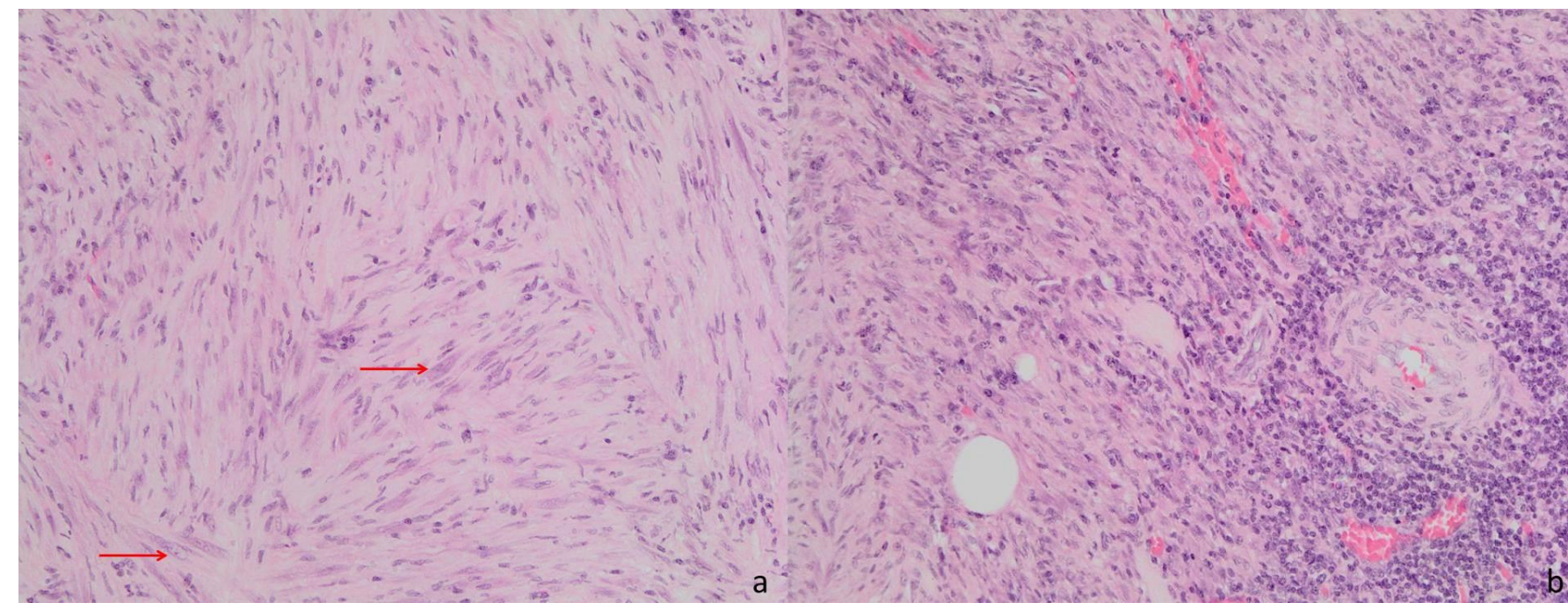

Figure 6: Thirty-one year old woman with inflammatory pseudotumor of the urinary bladder. Pathological study of the surgical specimen (hematoxylin and eosin staining, magnification: 20x). Spindle cell proliferation (a) with sparse mild nuclear atypia (arrows). Predominantly mononuclear inflammatory infiltrate (b).

\begin{tabular}{|l|l|}
\hline Etiology & Unknown. \\
\hline Incidence & Rare, 81 cases reported. \\
\hline Gender ratio & Male to female ratio of 11:6. \\
\hline Age predilection & Young adults, with an average age of 28 years. \\
\hline Risk factors & Recurrent cystitis and prior urinary bladder surgery. \\
\hline Clinical presentation & Hematuria, anemia, frequency and dysuria. Urinary tract obstruction may occur. \\
\hline Treatment & Conservative surgery: transurethral tumor resection or partial cystectomy. \\
\hline Prognosis & Good. No recurrence reported after surgery. \\
\hline Findings on imaging & $\begin{array}{l}\text { Exophytic or polypoid urinary bladder mass. } \\
\text { Ultrasound: hypoechoic or hyperechoic } \\
\text { CT: ranging from hypo to hyperattenuating } \\
\text { MR: hypointense on T1 and T2-weighted images } \\
\text { Contrast-enhanced CT and MR: early peripheral enhancement. Central areas may show late } \\
\text { enhancement. }\end{array}$ \\
\hline Findings on pathology & Spindle cell proliferation mixed with inflammatory infiltrate. \\
\hline
\end{tabular}

Table 1: Summary table for inflammatory pseudotumor of the urinary bladder. 


\begin{tabular}{|c|c|c|c|}
\hline & Ultrasound & CT & MRI \\
\hline $\begin{array}{l}\text { Inflammatory } \\
\text { pseudotumor }\end{array}$ & $\begin{array}{l}\text { Exophytic or polypoid bladder } \\
\text { mass with variable } \\
\text { echogenicity. }\end{array}$ & $\begin{array}{l}\text { Ranging from hypo to } \\
\text { hyperattenuating lesion. Early } \\
\text { peripheral enhancement. Central } \\
\text { areas may have late } \\
\text { enhancement. }\end{array}$ & $\begin{array}{l}\text { Hypointense on } \mathrm{T} 1 \text { and } \mathrm{T} 2 \text {-weighted } \\
\text { images. Early peripheral } \\
\text { enhancement. Central areas may have } \\
\text { late enhancement. }\end{array}$ \\
\hline $\begin{array}{l}\text { Urothelial } \\
\text { carcinoma }\end{array}$ & $\begin{array}{l}\text { Papillary hypoechoic masses } \\
\text { or areas of focal wall } \\
\text { thickening. }\end{array}$ & $\begin{array}{l}\text { Papillary or nodular mass or } \\
\text { focal wall thickening. Tumoral } \\
\text { calcification } 5 \% \text { of cases. Avid } \\
\text { and early contrast enhancement. }\end{array}$ & $\begin{array}{l}\text { Masses with intermediate signal } \\
\text { intensity on T2-weighted images. } \\
\text { Avid and early contrast enhancement. }\end{array}$ \\
\hline $\begin{array}{l}\text { Leiomyoma and } \\
\text { leiomyosarcoma }\end{array}$ & $\begin{array}{l}\text { Leiomyomas are smooth, } \\
\text { solid, homogeneous masses. } \\
\text { Leiomyosarcomas are more } \\
\text { heterogeneous and infiltrative. }\end{array}$ & $\begin{array}{l}\text { Solid, homogeneous or } \\
\text { heterogeneous masses. Variable } \\
\text { contrast enhancement. }\end{array}$ & $\begin{array}{l}\text { Intermediate signal intensity on T1- } \\
\text { weighted images and low signal } \\
\text { intensity on T2-weighted images. } \\
\text { Leiomyosarcomas are heterogeneous } \\
\text { on T2-weighted images. }\end{array}$ \\
\hline Endometriosis & Wall thickening. & $\begin{array}{l}\text { Wall thickening. Endometriotic } \\
\text { masses may enhance after } \\
\text { contrast administration. }\end{array}$ & $\begin{array}{l}\text { Hemorrhagic foci with high signal } \\
\text { intensity on fat-suppressed and non- } \\
\text { fat suppressed T1-weighted images. }\end{array}$ \\
\hline Schistosomiasis & $\begin{array}{l}\text { Wall thickening, } \\
\text { calcifications, associated } \\
\text { mass. }\end{array}$ & $\begin{array}{l}\text { Wall thickening, calcifications, } \\
\text { associated mass. }\end{array}$ & Wall thickening, associated mass. \\
\hline Tuberculosis & $\begin{array}{l}\text { Diffuse irregular wall } \\
\text { thickening. Reduced urinary } \\
\text { bladder capacity in chronic } \\
\text { phase. }\end{array}$ & $\begin{array}{l}\text { Thickened and contracted } \\
\text { urinary bladder. Fistulas and } \\
\text { sinus tracts. Ureteric dilatation. }\end{array}$ & $\begin{array}{l}\text { Thickened and contracted urinary } \\
\text { bladder. Fistulas and sinus tracts. } \\
\text { Ureteric dilatation. }\end{array}$ \\
\hline
\end{tabular}

Table 2: Differential diagnosis table for inflammatory pseudotumor of the urinary bladder.

\section{ABBREVIATIONS}

$\mathrm{CT}=$ computed tomography

$\mathrm{MR}=$ magnetic resonance

$\mathrm{TE}=$ echo time

$\mathrm{TI}=$ inversion time

$\mathrm{TR}=$ repetition time

\section{Online access}

This publication is online available at: www.radiologycases.com/index.php/radiologycases/article/view/2066

\section{Peer discussion}

Discuss this manuscript in our protected discussion forum at: www.radiolopolis.com/forums/JRCR

\section{KEYWORDS}

Inflammatory pseudotumor; plasma cell granuloma; inflammatory myofibroblastic tumor; urinary bladder; ultrasound; computed tomography; magnetic resonance imaging

\section{ACKNOWLEDGEMENTS}

We would like to thank Dr. Celso Matos, head of MRI department of Hôpital Erasme.

\section{Interactivity}

This publication is available as an interactive article with scroll, window/level, magnify and more features. Available online at www.RadiologyCases.com

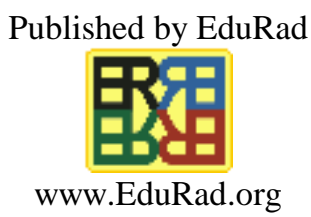

